\title{
Adalimumab effectiveness for the treatment of ankylosing spondylitis is maintained for up to 2 years: long-term results from the ATLAS trial
}

\author{
D van der Heijde, ${ }^{1}$ M H Schiff, ${ }^{2}$ J Sieper, ${ }^{3,4}$ A J Kivitz, ${ }^{5}$ R L Wong, ${ }^{6}$ H Kupper, \\ B A C Dijkmans, ${ }^{8,9}$ P J Mease, ${ }^{10} \mathrm{~J}$ C Davis Jr, ${ }^{11}$ for the ATLAS Study Group
}

${ }^{1}$ Department of Rheumatology, Leiden University Medical

Center, Leiden, The Netherlands;

${ }^{2}$ University of Denver, Denver,

Colorado, USA; ${ }^{3}$ Medical Department I, Rheumatology,

Benjamin Franklin Hospital, Free University Berlin, Germany:

${ }^{4}$ German Rheumatism Research

Center, Berlin, Germany;

${ }^{5}$ Altoona Center for Clinical

Research, Duncansville,

Pennsylvania, USA; ${ }^{6}$ Abbott

Laboratories, Parsippany, New Jersey, USA; ${ }^{7}$ Abbott GmbH

and $\mathrm{Co}, \mathrm{KG}$, Ludwigshafen, Germany; ${ }^{8}$ Department of

Rheumatology, VU University

Medical Center, Amsterdam,

The Netherlands; ${ }^{9}$ Jan van

Breemen Institute, Amsterdam,

The Netherlands: ${ }^{10}$ Seattle

Rheumatology Associates,

Swedish Medical Center,

University of Washington School

of Medicine, Seattle,

Washington, USA; ${ }^{11}$ Division of

Rheumatology, University of

California San Francisco, San

Francisco, California, USA

Correspondence to:

Dr D van der Heijde, Department of Rheumatology, LUMC, PO Box 9600, 2300 RC Leiden, The Netherlands; d.vanderheijde@ kpnplanet.nl

Accepted 3 August 2008

Published Online First

12 August 2008

\section{ABSTRACT}

Objective: To determine the long-term effect of adalimumab on patients with ankylosing spondylitis (AS) who participated in the Adalimumab Trial Evaluating LongTerm Efficacy and Safety in AS (ATLAS), a randomised, double-blind, placebo controlled, 24-week trial.

Methods: Patients received adalimumab $40 \mathrm{mg}$ every other week (eow) or placebo for 24 weeks in ATLAS. At week 24, patients were switched to open-label adalimumab 40 mg eow. Efficacy measures included 20\% improvement in the Assessment in SpondyloArthritis International Society (ASAS) criteria (ASAS20), ASAS40 and ASAS partial remission responses and changes in individual components of the ASAS20 response evaluations, for example, Bath AS Functional Index (BASFI) and Bath AS Disease Activity Index (BASDAl). Two-year interim data were analysed based on the total duration of adalimumab exposure, irrespective of the treatment randomisation group.

Results: At 2 years, 255 (82.0\%) of the original 311 ATLAS patients continued receiving adalimumab treatment. Improvements in ASAS responses observed in ATLAS were sustained during long-term treatment; $64.5 \%$ (200/310) were ASAS20 responders, 50.6\% (157/310) were ASAS40 responders and 33.5\% (104/310) had maintained ASAS-defined partial remission. Changes in individual ASAS response components were sustained or improved during long-term adalimumab treatment. From ATLAS baseline to 2 years of adalimumab exposure, respectively, BASDAl improved from 6.3 (SD 1.7) to 2.4 (SD 2.3) and BASFl improved from 5.2 (SD 2.4) to 2.9 (SD 2.5). Adalimumab was well tolerated. No cases of tuberculosis, congestive heart failure, lupus-like symptoms, or demyelinating disease were reported.

Conclusions: Adalimumab reduced the signs and symptoms of AS and induced partial remission for up to 2 years. The long-term safety profile was similar to the short-term safety profile.

Trial registration information: NCT00085644

Ankylosing spondylitis (AS) is a chronic, progressive inflammatory disease that primarily affects the spine and sacroiliac joints. The onset of AS is typically in the third decade of life. AS has a standardised prevalence rate of $0.55 \%$ among white patients $^{1}$ and is linked with HLA-B27 positivity. ${ }^{2}$ Patients with AS can experience significant longterm functional impairment and disability, with reduced quality of life and an increased risk of comorbid conditions. AS is associated with significant direct and indirect costs to the patient and the healthcare system. ${ }^{3}$

The essential role of tumour necrosis factor (TNF) in AS has been shown by the efficacy of TNF blockade in the treatment of AS. The efficacy of TNF antagonists, adalimumab, etanercept and infliximab, has been demonstrated in short-term clinical studies, ${ }^{4-10}$ as well as in long-term studies of etanercept (up to 2 years) ${ }^{11}{ }^{12}$ and infliximab (up to 3 years) ${ }^{13-15}$

The Adalimumab Trial Evaluating Long-term Efficacy and Safety for AS (ATLAS) demonstrated that adalimumab, a fully human anti-TNF monoclonal antibody, improves the signs and symptoms of AS for up to 24 weeks and is generally well tolerated. ${ }^{16}$ During short-term treatment, adalimumab also improved the health-related quality of life (HRQoL) and physical function of patients with AS. ${ }^{17}$ In addition, adalimumab reduced pain, fatigue and stiffness, three of the most common concerns of patients with AS. ${ }^{18}$ Patients completing the 24-week, placebo controlled, double-blind portion of ATLAS were eligible for enrollment in an open-label extension study (which is still ongoing) designed to determine the safety and efficacy of adalimumab treatment in patients with active AS and the impact of adalimumab on HRQoL during up to 4.5 years of treatment. Herein, we report the 2-year interim results of this open-label extension study.

\section{METHODS}

\section{Patients}

Patients were 18 years of age or older, diagnosed with definitive AS based on the modified New York criteria $^{19}$ and fulfilling at least two of the following three criteria: (1) Bath AS Disease Activity Index (BASDAI) score 4 or greater; (2) morning stiffness for $1 \mathrm{~h}$ or longer and (3) visual analogue scale (VAS) score for total back pain 4 or greater on a scale of 0 to 10. Patients also had an inadequate response to at least one non-steroidal anti-inflammatory drug and may (but were not required to) have failed treatment with at least one disease-modifying antirheumatic drug. Additional inclusion and exclusion criteria have been published previously. ${ }^{16}$

\section{Study design}

Detailed efficacy, HRQoL and safety methods for the first 24-week period of the ATLAS study have been published previously. ${ }^{17}$ Patients were randomly assigned in a 2:1 ratio to receive either a online under the BMJ Journals unlocked scheme, see http:// ard.bmj.com/info/unlocked.dtl 


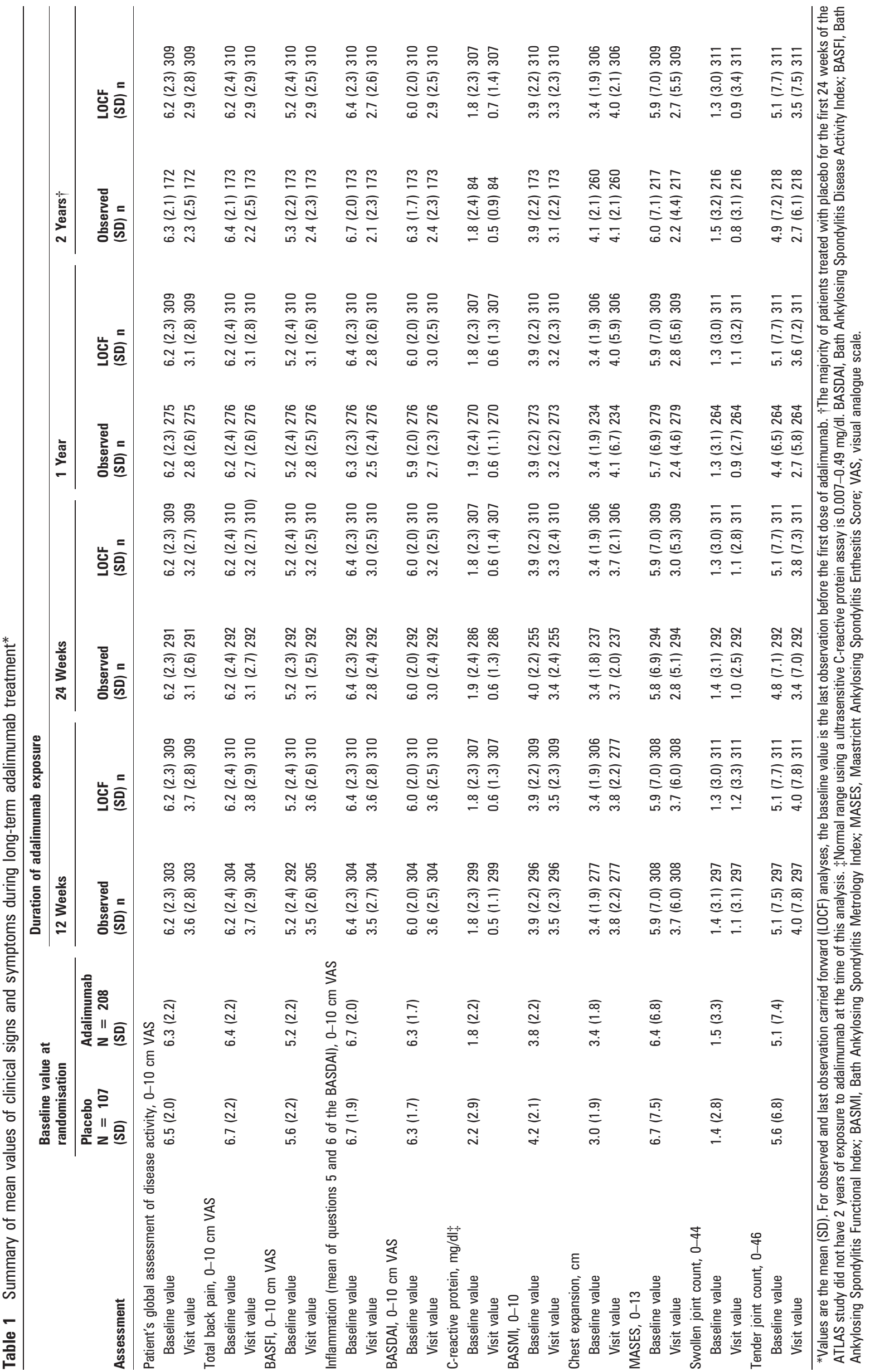


subcutaneous injection of adalimumab (Humira; Abbott Laboratories, Abbott Park, Illinois, USA) $40 \mathrm{mg}$ every other week (eow) or matching placebo during the initial 24-week, randomised, double-blind, placebo controlled period. Based on evaluation by the investigator, patients who did not achieve at least a $20 \%$ response according to the Assessment in SpondyloArthritis International Society (ASAS) criteria for improvement (ASAS20) at double-blind weeks 12, 16, or 20 had the following three options: (1) continue blinded study medication to week 24; (2) receive early-escape therapy (ie, open-label adalimumab $40 \mathrm{mg}$ eow before week 24); or (3) discontinue from the study. Patients who did not achieve an ASAS20 response after 12 weeks or more of open-label treatment may have been treated with adalimumab $40 \mathrm{mg}$ every week. The 24 -week, double-blind study period was followed by an open-label extension phase, during which all patients received adalimumab $40 \mathrm{mg}$ eow or weekly for up to an additional 4.5 years. Clinic visits occurred every 6 weeks through the double-blind period and then at weeks $30,40,52$, 64, 76, 88 and 104 .

\section{Measures}

The primary efficacy assessment in the randomised, controlled portion of ATLAS was the ASAS20. ${ }^{20}$ The ASAS40, ASAS 5/6,
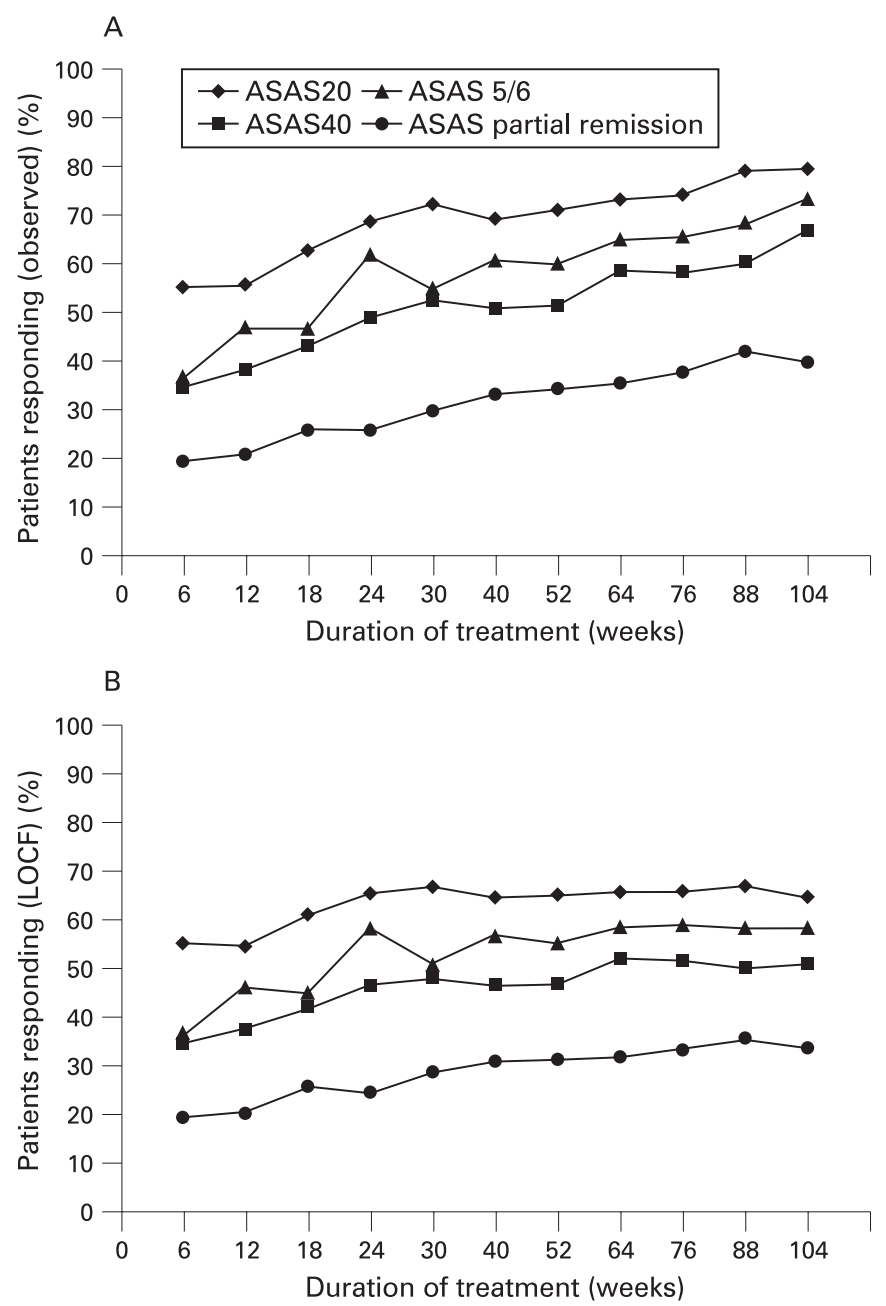

Figure 1 Assessment in Ankylosing Spondylitis International Working Group (ASAS) responses by duration of adalimumab treatment. (A) Observed data. (B) Last observation carried forward (LOCF) data $(N=311)$. and ASAS-defined partial remission responses ${ }^{21}$ were also evaluated. For the determination of ASAS 5/6 responses, Creactive protein (CRP) concentrations were used as the acute phase reactant and the Bath AS Metrology Index (BASMI) was used as the metrology assessment. ${ }^{22}$ Additional efficacy endpoints for ATLAS were previously described in detail ${ }^{16}$ and included the patient's global assessment of disease activity during the past week, represented by the score on a $0-10 \mathrm{~cm}$ horizontal VAS; pain, as represented by the total back pain score on a 0-10 cm VAS; the Bath AS Functional Index (BASFI) score $\left(0-10 \mathrm{~cm}\right.$ VAS) $;^{23}$ inflammation, as determined by the mean of the severity and duration of morning stiffness based on $0-10 \mathrm{~cm}$ VAS scores (mean of questions 5 and 6 of the BASDAI) ${ }^{24}$ the BASMI score (0-10); CRP concentrations; BASDAI 50 response; and enthesitis, as assessed by the Maastricht AS Enthesitis Score (MASES; range 0-13) ${ }^{25}$

HRQoL measures were also completed at baseline, at weeks 12 and $24^{17}$ and after 1 and 2 years of adalimumab exposure, and included the AS Quality of Life (ASQoL) questionnaire ${ }^{26}$ as well as the Short Form 36 Health Survey (SF-36). The ASQoL is a disease-specific instrument designed to measure $\mathrm{HROOL}$ in patients with AS and has 18 yes or no questions with a total score of $0-18$. Lower ASQoL scores represent a better AS-specific HRQoL, and a reduction of at least 1.8 points was defined a priori as the minimum clinically important difference (MCID). Patients completed the SF-36 version 1 based on a 4-week recall period. ${ }^{27}$ Differences of 3.0 or more points in the SF-36 physical component summary (PCS) or mental component summary (MCS) exceed the a priori definition for MCID and are considered to be clinically meaningful. Adverse events (AE), vital signs, physical examinations and laboratory assessments were routinely evaluated.

\section{Statistical analysis}

The data cutoff for the 2-year interim analysis of the open-label extension of ATLAS occurred 2 years after the last patient's first visit in the study (that is, the start of the double-blind period). Data are reported based on adalimumab exposure for each patient, which was defined beginning with the first dose of adalimumab administered either during the double-blind period or the open-label period of the study. Because some patients were treated with placebo for the first 24 weeks of the study, not all patients had 2 years of exposure to adalimumab at the time of this analysis. If a patient received placebo during the double-blind period of ATLAS, efficacy and HROoL data collected during that period were not included in this analysis of the efficacy of long-term adalimumab treatment. Only efficacy data collected following a patient's first dose of adalimumab are presented. For all efficacy and HRQoL measures, baseline for all analyses was defined as the last observation before the first dose of adalimumab. Efficacy results presented for the 2-year open-label extension are presented as observed data for all patients who received at least one dose of adalimumab; last observation carried forward (LOCF) analyses are also presented for all patients who received at least one dose of adalimumab. Safety assessments were based on observed data reported following any adalimumab exposure.

\section{RESULTS}

Patient enrollment and disposition

The data for this study were collected between 27 January 2004 and 10 July 2006. Of the 315 patients enrolled in the double-blind period, 208 were randomly assigned to receive adalimumab $40 \mathrm{mg}$ 
Table 2 Baseline demographic and clinical characteristics for patients who switched to weekly adalimumab treatment and patients who received adalimumab $40 \mathrm{mg}$ every other week*

\begin{tabular}{llc}
\hline Characteristic & $\begin{array}{l}\text { Adalimumab } \mathbf{4 0} \mathbf{~ m g} \\
\text { weekly } \\
\text { (N = 72) }\end{array}$ & $\begin{array}{l}\text { Adalimumab } \mathbf{4 0 ~} \mathbf{~ m g} \\
\text { every other week } \\
\text { (N = 239) }\end{array}$ \\
\hline Male, $\mathrm{n}(\%)$ & $46(63.9)$ & $187(78.2)$ \\
White, $\mathrm{n}(\%)$ & $69(95.8)$ & $230(96.2)$ \\
Age, years (SD) & $46.1(10.0)$ & $41.2(11.8)$ \\
Disease duration, years (SD) & $10.7(9.0)$ & $11.1(9.6)$ \\
HLA-B27 positive, $\mathrm{n}(\%)$ & $52(72.2)$ & $193(80.8)$ \\
Patient's global assessment of disease activity, cm (SD) & $7.0(2.1)$ & $6.2(2.1)$ \\
Total back pain, cm (SD) & $7.2(2.0)$ & $6.3(2.1)$ \\
Inflammation (mean of questions 5 and 6 of the BASDAl), cm (SD) & $7.3(1.9)$ & $6.5(2.0)$ \\
BASFl, cm (SD) & $6.1(2.3)$ & $5.2(2.1)$ \\
BASDAl, cm (SD) & $6.9(1.6)$ & $6.1(1.7)$ \\
C-reactive protein, mg/dl (SD) $\dagger$ & $1.5(1.6)$ & $2.0(2.7)$ \\
BASMI, 0-10 (SD) & $4.5(2.1)$ & $3.8(2.2)$ \\
Chest expansion, cm (SD) & $2.9(1.5)$ & $3.4(1.9)$ \\
MASES, 0-13 (SD) & $8.4(7.6)$ & $5.9(6.7)$ \\
\hline
\end{tabular}

*Values are mean (SD) unless otherwise noted. †Normal range using an ultrasensitive C-reactive protein assay is 0.007-0.49 mg/ dl. BASDAl, Bath Ankylosing Spondylitis Disease activity Index; BASFI, Bath Ankylosing Spondylitis Functional Index; BASMI, Bath Ankylosing Spondylitis Metrology Index; MASES, Maastricht Ankylosing Spondylitis Enthesitis Score.

eow, 107 were assigned to receive placebo; 296 completed the 24week double-blind period. ${ }^{16}$ At baseline of the double-blind period, the mean BASDAI scores for both placebo and adalimumab groups were 6.3 (SD 1.7). Of the 311 patients who received at least one dose of adalimumab (either during the randomised, controlled portion of ATLAS or during the open-label extension), 261 (83.9\%) were receiving adalimumab treatment in the open-label extension study at the time this analysis was completed.

\section{Demographic and clinical characteristics}

Patients were primarily male (74.9\%), white (96.1\%), and HLAB27 positive (78.8\%). The mean patient age was 42.3 years (SD 11.56, range 18-71). The mean duration of disease was 11.0 years (SD 9.5, range 0.1-48.4). Baseline clinical characteristics for the randomised, double-blind study ${ }^{16}$ and the current extension study are displayed in table 1 .

\section{Adalimumab exposure}

Of the 311 patients who received at least one dose of adalimumab, median exposure to adalimumab was 2 years (range 14-896 days). Seventy per cent of patients (218/311) received adalimumab for at least 1.75 years. Seventy-two $(23.2 \%)$ patients who were ASAS20 non-responders in the randomised, controlled portion of the study switched to adalimumab $40 \mathrm{mg}$ weekly. Of these 72 patients, 53 had received weekly treatment for at least 1 year and two had received weekly adalimumab for 2 years at the time of this analysis.

\section{Long-term efficacy}

Treatment with adalimumab significantly reduced the signs and symptoms of AS at weeks 12 and 24. The magnitude of improvement was sustained through 2 years of adalimumab exposure (fig $1 \mathrm{~A}$ and $\mathrm{B}$ ). The percentage of patients achieving ASAS20, ASAS40, ASAS $5 / 6$ and ASAS partial remission responses was sustained from week 24 to up to 2 years of adalimumab exposure (fig $1 \mathrm{~A}$ and $\mathrm{B}$ ). During short-term treatment (24 weeks of adalimumab exposure), 65.2\% (202/ $310)$ of patients were ASAS20 responders, 46.1\% (143/310) were ASAS40 responders, 58.6\% (181/309) were ASAS 5/6 responders and $24.2 \%(75 / 310)$ achieved ASAS partial remission based on
LOCF analyses (fig 1B). During long-term treatment (2 years of adalimumab exposure), 64.5\% (200/310) patients were ASAS20 responders, $50.6 \%(157 / 310)$ were ASAS40 responders, $58.9 \%$ $(182 / 309)$ were ASAS 5/6 responders and $33.5 \%(104 / 310)$ achieved ASAS partial remission based on LOCF analyses (fig 1B). Improvements in the individual components of the ASAS20 response evaluations were also sustained during longterm adalimumab treatment (table 1).

Mean values for baseline demographics and clinical characteristics for patients who switched from adalimumab $40 \mathrm{mg}$ eow to $40 \mathrm{mg}$ weekly were similar to mean values for the overall group of patients who received adalimumab $40 \mathrm{mg}$ eow throughout (table 2), with a tendency to a somewhat greater level of disease activity at baseline. After 6 weeks of weekly adalimumab therapy, 14 of 61 (23.0\%) patients had an ASAS20 response, six of 61 (9.8\%) patients had an ASAS40 response and eight of $61(13.1 \%)$ had a BASDAI 50 response. After 1 year of receiving adalimumab $40 \mathrm{mg}$ weekly, 18 of 53 patients (34.0\%) achieved an ASAS20 response, eight of 53 (15.1\%) achieved an ASAS40 response and eight of 53 (15.1\%) achieved a BASDAI 50 response (observed data); these 53 patients were ASAS nonresponders before being switched to weekly adalimumab treatment.

Improvements in mean BASDAI scores were sustained for up to 2 years (table 1). At least a $50 \%$ improvement on the BASDAI was attained by $43.8 \%(133 / 304)$ of patients after 3 months of adalimumab exposure; $53.8 \%(157 / 292)$ after 6 months; $60.5 \%$ $(167 / 276)$ after 1 year and $70.5 \%(122 / 173)$ after 2 years (observed data). Based on LOCF analysis, a BASDAI 50 response was attained by $42.9 \%(133 / 310)$ of patients after 3 months of adalimumab exposure; $51.3 \%(159 / 310)$ after 6 months; $55.8 \%$ $(173 / 310)$ after 1 year and 58.7\% (182/310) after 2 years.

Improvements in the signs and symptoms of AS were sustained during long-term adalimumab treatment (table 1). Significant reductions in CRP concentrations were sustained through 2 years of treatment. The statistically significant improvement in enthesitis (as measured by the MASES) observed during the 24 -week portion of ATLAS continued to improve during 2 years of adalimumab treatment. The observed mean change in the MASES was a 3.0 point reduction after 24 weeks of adalimumab treatment compared with a 3.8 point 


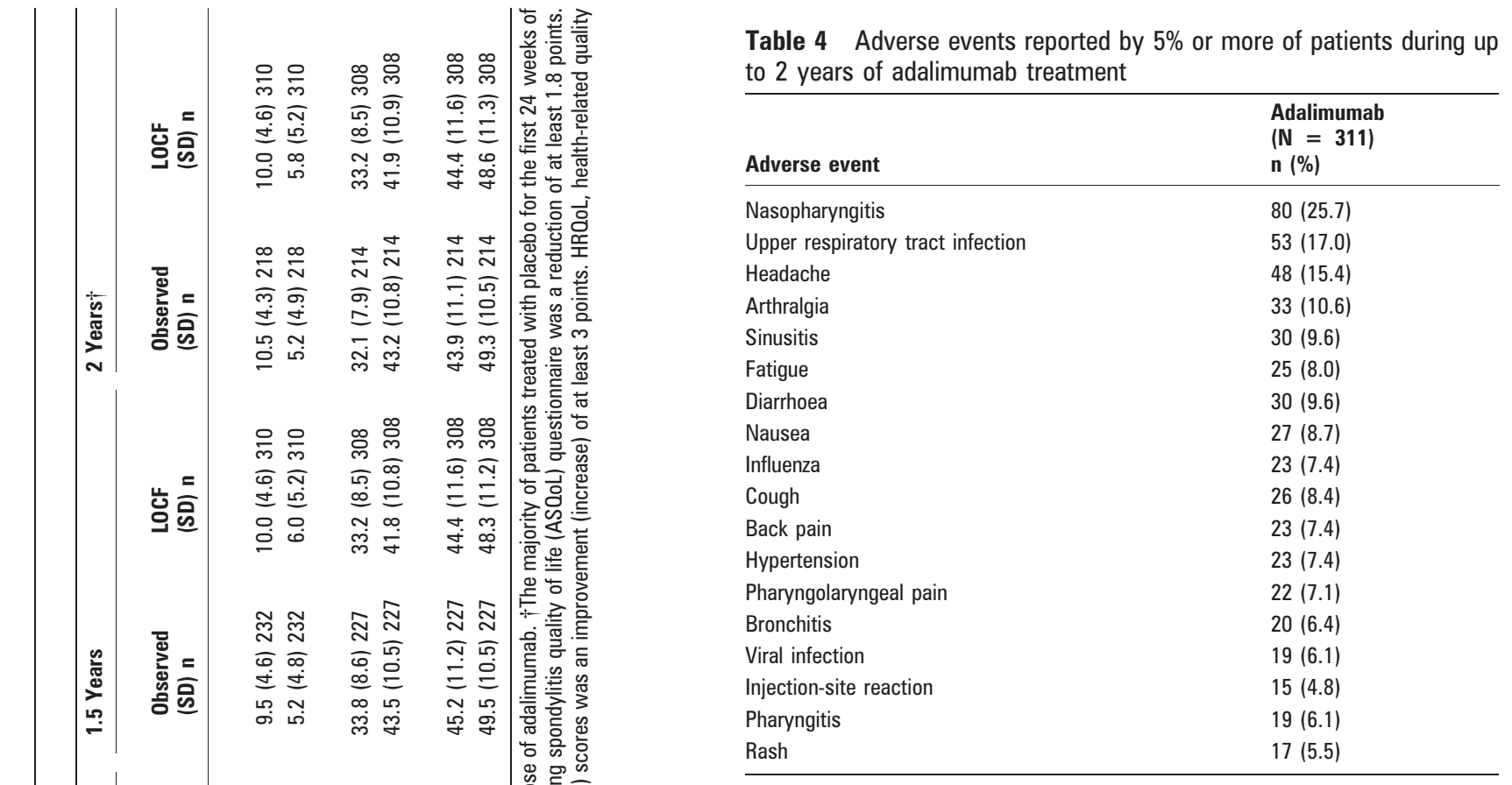

reduction after 2 years of adalimumab treatment. Long-term adalimumab treatment was also associated with maintenance of an improvement in spinal metrology, as shown by a decrease in mean BASMI scores over time (table 1). The improvement in the overall BASMI score was driven by statistically significant improvements in three of five components of the BASMI score (eg, lumbar side flexion, cervical rotation and intermalleolar distance; $p<0.05$ for each) at week 24 of the double-blind portion of the study in adalimumab compared with placebotreated patients. ${ }^{16}$ The tragus-to-wall and anterior lumbar flexion components did not respond to adalimumab treatment. Similarly, chest expansion did not change significantly in adalimumab-treated patients.

\section{Long-term HROoL}

Changes over time in HRQoL assessments are summarised in table 3. Improvements based on the ASOoL were substantial and statistically significant compared with placebo by week 24 and steadily improved over time. The magnitude of improvement was more than twice the prespecified MCID of at least 1.8 points at every time point measured. Improvements in the SF36 PCS score were substantial and exceeded the MCID of 3 points for up to 2 years of adalimumab treatment. Although the change from baseline in SF-36 MCS scores was not statistically significantly different from placebo at week 24 , the mean improvement in SF-36 MCS scores also exceeded the MCID for up to 2 years of adalimumab treatment. The mean changes in SF-36 MCS scores were smaller in magnitude than the improvements in the SF-36 PCS and were stable over time.

\section{Safety}

Overall, adalimumab was well tolerated. The safety profile during long-term treatment was consistent with that observed during short-term treatment. ${ }^{16}$ During up to 2 years of adalimumab exposure, the most common AE (reported by $\geqslant 5 \%$ of patients) were nasopharyngitis, upper respiratory tract infection and headache (table 4). For the patients treated with adalimumab during the double-blind period and then during the open-label period, respectively, the following AE rates per 100 
Table 5 Summary of TNF-associated AE of interest during up to 2 years of adalimumab treatment

\begin{tabular}{|c|c|c|c|}
\hline \multirow[b]{2}{*}{ Adverse event } & \multicolumn{3}{|c|}{ Adalimumab exposure } \\
\hline & $\begin{array}{l}\text { Weekly } \\
\text { (N = 72) } \\
\mathrm{n}(\%)\end{array}$ & $\begin{array}{l}\text { Any } \\
\text { (N = 311) } \\
n(\%)\end{array}$ & $\begin{array}{l}\text { Any } \\
\text { (PY = 533.7) } \\
\text { AE/100 PY }\end{array}$ \\
\hline Any $A E$ & $62(86.1)$ & $293(94.2)$ & 445.6 \\
\hline At least possibly drug-related $\mathrm{AE}$ & $31(43.1)$ & $174(55.9)$ & 107.7 \\
\hline Serious $A E$ & $5(6.9)$ & $48(15.4)$ & 10.5 \\
\hline At least possibly drug-related serious $\mathrm{AE}$ & 0 & $17(5.5)$ & 3.7 \\
\hline AE leading to discontinuation of study drug & $1(1.4)$ & $24(7.7)$ & 4.5 \\
\hline Infectious $A E$ & $37(51.4)$ & $213(68.5)$ & 109.7 \\
\hline Serious infectious $A E$ & $1(1.4)$ & $6(1.9)$ & 1.1 \\
\hline Appendicitis & 0 & $1(0.3)$ & 0.2 \\
\hline Bacteraemia & 0 & $1(0.3)$ & 0.2 \\
\hline Beta-haemolytic streptococcal infection & $1(1.4)$ & $1(0.3)$ & 0.2 \\
\hline Cellulitis* & 0 & $1(0.3)$ & 0.2 \\
\hline Pneumonia $†$ & 0 & $1(0.3)$ & 0.2 \\
\hline Rectal abscess $\dagger$ & 0 & $1(0.3)$ & 0.2 \\
\hline Drug hypersensitivity-related $\mathrm{AE}$ & 0 & $1(0.3)$ & 0.4 \\
\hline Malignancies & $1(1.4)$ & $4(1.3)$ & 0.7 \\
\hline Basal-cell carcinoma & 0 & $1(0.3)$ & 0.2 \\
\hline Malignant melanoma & $1(1.4)$ & $1(0.3)$ & 0.2 \\
\hline Non-Hodgkin's lymphoma & 0 & $1(0.3)$ & 0.2 \\
\hline Squamous cell carcinoma of the skin & 0 & $1(0.3)$ & 0.2 \\
\hline Injection-site reactions & $2(2.8)$ & $42(13.5)$ & 17.6 \\
\hline Opportunistic infections & 0 & $4(1.3)$ & 0.7 \\
\hline Tuberculosis & 0 & 0 & 0 \\
\hline Demyelinating disease & 0 & 0 & 0 \\
\hline Deaths & 0 & 0 & 0 \\
\hline
\end{tabular}

*Possibly related to adalimumab treatment. $\uparrow$ Probably related to adalimumab treatment. $\ddagger \mathrm{All}$ four cases were oral candidiasis. $\mathrm{AE}$, adverse event; PY, patient-years; TNF, tumour necrosis factor.

patient-years were observed: serious $\mathrm{AE}, 10.2$ versus 10.5; serious infectious $\mathrm{AE}, 0$ versus 1.1; $\mathrm{AE}$ leading to discontinuation, 3.8 versus 4.5 and malignant $A E, 0.0$ versus 0.9 .

The numbers and percentages of patients who experienced TNF-associated AE of interest are summarised in table 5. There were no cases of tuberculosis, congestive heart failure, lupus-like symptoms, or demyelinating disease and no deaths were reported. There were six serious infectious $\mathrm{AE}(1.9 \%$ of patients). Of these, three were considered possibly or probably related to the study drug. One patient (0.3\%) had an adalimumab-related hypersensitivity reaction. Weekly administration of adalimumab did not cause any additional safety issues (table 4).

Malignancies occurred in four patients $(1.3 \%)$. One patient, a 56-year-old man, was diagnosed with non-Hodgkin lymphoma after 176 days of treatment. The non-Hodgkin lymphoma was considered by the investigator to be possibly related to the study drug. The patient was discontinued from the study and observed by his oncologist. The patient's lymph nodes regressed without chemotherapy and the patient did not require any treatment at last contact. The other three cases of malignancies included two cases of non-melanoma skin cancer (one case of squamous-cell carcinoma and one case of basal-cell carcinoma) and one case of malignant melanoma. All three patients were treated by surgical excision of the affected site.

Of the 311 patients who received at least one dose of adalimumab, 94 had a history of uveitis, seven had a history of Crohn's disease and 10 had a history of ulcerative colitis. Twelve of 311 (3.9\%) patients developed uveitis during follow-up. Of these 12, three had new-onset uveitis and nine patients experienced flares. One patient with a history of ulcerative colitis had a flare of ulcerative colitis. One patient with no previous history of inflammatory bowel disease developed Crohn's disease. None of the patients with a history of Crohn's disease experienced a flare.

There were no clinically meaningful changes in clinical chemistry values, liver enzymes, or vital signs during long-term adalimumab exposure.

\section{DISCUSSION}

The placebo-controlled portion of ATLAS demonstrated that adalimumab treatment improves the signs and symptoms of AS for up to 24 weeks, beginning within 2 weeks of treatment. ${ }^{16}$ ATLAS is the largest long-term study of a TNF antagonist for the treatment of active AS, with 255 patients continuing adalimumab treatment at the time of this 2-year analysis. The BASDAI 50, ASAS20, ASAS40, ASAS 5/6 and ASAS partial remission responses that were achieved during the initial 24week, double-blind period of ATLAS were sustained for up to 2 years of treatment. Improvements in individual components of the ASAS response (patient's global assessment of disease activity, pain, function and inflammation) were also sustained for up to 2 years of adalimumab treatment.

The progressive restriction in spinal mobility experienced by patients with AS contributes to significant functional disability and reduced HRQoL. Adalimumab treatment led to sustained improvements in physical function and mobility during longterm treatment. After 2 years of adalimumab treatment, $75 \%$ of patients experienced a sustained improvement in BASMI. Not all assessments of spinal mobility that were evaluated in the ATLAS trial demonstrated a significant difference between the treatment groups. However, it is known that the tragus-to-wall, anterior lumbar flexion and chest expansion are, in general, not very responsive measures, especially not in established disease. 
The improvement in enthesitis (as measured by the MASES) that patients experienced at week 24 in the randomised, controlled portion of ATLAS increased in magnitude through 1 and 2 years of adalimumab treatment.

In addition, long-term adalimumab treatment was associated with improved HRQoL as demonstrated by substantial and sustained improvements assessed using a disease-specific measure (ASQoL). The improvements in SF-36 PCS scores demonstrated that adalimumab treatment is associated with an improvement in physical HRQoL that exceeded the MCID and increased over time. These HRQoL results are consistent with long-term studies of etanercept ${ }^{11}$ and infliximab. ${ }^{14} 28$

The ASAS20, ASAS40 and BASDAI 50 response rates after 1 year of weekly adalimumab therapy indicate that increasing the dosage of adalimumab may benefit some patients and may be considered before switching to an alternative therapy.

Adalimumab was generally well tolerated during up to 2 years of treatment. There were no unexpected safety concerns during this long-term study. Of note, patients with AS who received weekly adalimumab treatment did not experience a higher rate of $\mathrm{AE}$ compared with patients who received treatment eow. The overall safety profile of adalimumab is similar to other anti-TNF therapies used for the treatment of $\mathrm{AS}^{7}{ }^{911} 1228$ and is consistent with the safety profile of adalimumab during long-term treatment of patients with rheumatoid arthritis or psoriatic arthritis. ${ }^{29-34}$

\section{CONCLUSIONS}

Adalimumab treatment for up to 2 years reduced the signs and symptoms of AS and induced a partial remission. The substantial improvements in spinal mobility and enthesitis that were observed in ATLAS continued to increase during long-term therapy. The HRQoL of patients with active AS was also substantially improved during long-term adalimumab treatment. Adalimumab was generally well tolerated; the long-term safety profile was similar to the short-term safety profile. Continued evaluation of these patients will further define the long-term safety and efficacy profile of adalimumab for the treatment of patients with active AS.

Acknowledgements: The authors thank Eric D Bauer, Shyanne M Douma, Hans $\mathrm{H}$ Kissel and all study-site coordinators for assistance with study conduct; Shaila Ballal, for statistical analyses; Yuan He and Winnie Lau, for data management; Dana L Randall of JK Associates and Michael A Nissen of Abbott Laboratories, for assistance with manuscript preparation and revision. The authors also thank all members of the ATLAS Study Group for their contributions to this long-term study and their continued care of all participating patients: Charles Birbara (Clinical Pharmacology Study Group, Worcester, Massachusetts, USA); Michael Borofsky (Arthritis and Osteoporosis Center, Clinical Research Center of Reading, West Reading, Pennsylvania, USA); Johan Bratt (Karolinska University Hospital, Karolinska, Sweden); Maxime Breban (Hospital Ambroise Paris, Boulogne-Billancourt, France); Fabrizio Cantini (Stabilimento Ospedaliero Misericordia e Dolce, Prato, Italy); Eduardo Collantes (Hospital Universitario Reina Sofia, Cordova, Spain); John J Cush (Presbyterian Hospital of Dallas, Dallas, Texas, USA); Gino DiVittorio (Coastal Clinical Research, Mobile, Alabama, USA); John Flynn (Johns Hopkins University, Baltimore, Maryland, USA): Dale Halter (Houston Institute for Clinical Research, Houston, Texas, USA); Christopher Jackson (University of Utah School of Medicine, Salt Lake City, Utah, USA); Brian Keroack (Portland, Maine, USA); Joel Kremer (Center for Rheumatology, Albany, New York, USA); Richard Lautzenheiser (Rheumatology Associates, Indianapolis, Indiana, USA); Xavier Le Loet (Hospital de Bois-Guillaume, Rouen, France); Alan K Matsumoto (Center for Rheumatology and Bone Research, Wheaton, Maryland, USA); Phillip J Mease (Seattle Rheumatology Associates, Seattle, Washingron, USA); Boel Morck (Sahlgrenska Universitetssjukhus, Gothenburg, Sweden); Larry Moreland (University of Pittsburgh, Pittsburgh, Philadelphia, USA; affiliated with the University of Alabama at Birmingham at the time of ATLAS initiation); James Morgan, (Dartmouth-Hitchcock Medical Center, Lebanon, NH); Juan Mulero (Hospital Universitario Puerta de Hierro, Madrid, Spain); Ignazio Olivieri (Ospedale S Carlo di Potenza, Potenza, Italy); William Palmer (Westroads Medical Group, Omaha, Nebraska, USA); Kaushik Patra (Abbott Laboratories, Parsippany, New Jersey, USA); Eric Ruderman (Feinberg School of
Medicine of Northwestern University, Chicago, Illinois, USA); Peggy Rupp (Boise Arthritis Clinic, Boise, Idaho, USA); Carlo Salvarani (Arcispedale S Maria Nuova, Reggio Emilia, Italy); Michael Sayers (Arthritis Associates, Colorado Springs, Colorado, USA); David Scott (Norfolk and Norwich University Hospital NHS Trust, Norfolk, UK); Roger D Sturrock (Royal Infirmary, Glasgow, UK); Juan Torre (Hospital Monte Naranco, Oviedo, Spain); Eric Veys (UZ Ghent, Ghent, Belgium); Rene Westhovens (UZ Gasthursberg, Leuven, Belgium); Larry Willis (Lynn Health Science Institute, Oklahoma City, Oklahoma, USA); Brian P Wordsworth (Nuffield Orthopaedic Centre, Oxford, UK) and Henning Zeidler (Medizinische Hochschule Hannover, Hannover, Germany).

Funding: The research reported here and the preparation of this manuscript were funded by Abbott Laboratories. The ATLAS Study Group included experts from academic institutions in Europe and the USA and members of Abbott Laboratories who designed the original clinical trial. Clinical data were collected and analysed by Abbott Laboratories. All authors contributed to manuscript development and reviewed and approved the content of the submitted manuscript.

Competing interests: DvdH has received consulting fees, research grants and/or speaking fees from Abbott Laboratories, Amgen, Aventis, Bristol Meyers Squibb, Centocor, Pfizer, Roche, Schering-Plough, UCB and Wyeth. MHS has received reimbursements, speaking fees, research funds and consulting fees. JS has received consulting fees, research grants and/or speaking fees from Abbott Laboratories, Bristol Meyers Squibb, Centocor, Pfizer, Roche, Schering-Plough, UCB and Wyeth. AJK has received consulting fees, research grants and/or speaking fees from Abbott Laboratories, Amgen, Bristol Meyers Squibb, Pfizer, Roche, Novartis, Schering-Plough, UCB and Wyeth. BACD has received research grants from Abbott, Schering-Plough and Wyeth. PJM has received research grants and speaker's bureau honorarium from Abbott Laboratories and has served as a consultant for Abbott Laboratories. JCD has received speaking fees from Abbott and served as the University of California San Francisco primary investigator for the ATLAS study. RLW and HK are employees of Abbott and own shares of Abbott stock.

Ethics approval: Ethics approval was obtained.

Patient consent: Obtained.

\section{REFERENCES}

1. Akkoc N, Khan MA. Overestimation of the prevalence of ankylosing spondylitis in the Berlin study: comment on the article by Braun et al [letter]. Arthritis Rheum 2005:52:4048-9.

2. Sieper J, Rudwaleit M, Khan MA, Braun J. Concepts and epidemiology of spondyloarthritis. Best Pract Res Clin Rheumatol 2006;20:401-17.

3. Boonen A, van der Linden SM. The burden of ankylosing spondylitis. J Rheumatol 2006;33(Suppl 78):4-11

4. Braun J, Brandt J, Listing J, Zink A, Alten R, Golder W, et al. Treatment of active ankylosing spondylitis with infliximab: a randomised controlled multicentre trial. Lancet 2002;359:1187-93.

5. Braun J, Landewe R, Hermann KG, Han J, Yan S, Williamson P, et al. Major reduction in spinal inflammation in patients with ankylosing spondylitis after treatment with infliximab: results of a multicenter, randomized, double-blind, placebocontrolled magnetic resonance imaging study. Arthritis Rheum 2006;54:1646-52.

6. Calin A, Dijkmans BA, Emery P, Hakala M, Kalden J, Leirisalo-Repo M, et al. Outcomes of a multicentre randomised clinical trial of etanercept to treat ankylosing spondylitis. Ann Rheum Dis 2004;63:1594-600.

7. Davis JC Jr, Van Der Heijde D, Braun J, Dougados M, Cush J, Clegg DO, et al. Recombinant human tumor necrosis factor receptor (etanercept) for treating ankylosing spondylitis: a randomized, controlled trial. Arthritis Rheum 2003;48:3230-6.

8. Rudwaleit M, Baraliakos X, Listing J, Brandt J, Sieper J, Braun J. Magnetic resonance imaging of the spine and the sacroiliac joints in ankylosing spondylitis and undifferentiated spondyloarthritis during treatment with etanercept. Ann Rheum Dis 2005;64:1305-10

9. van der Heijde D, Dijkmans B, Geusens P, Sieper J, DeWoody K, Williamson P, et al. Ankylosing Spondylitis Study for the Evaluation of Recombinant Infliximab Therapy Study Group. Efficacy and safety of infliximab in patients with ankylosing spondylitis: results of a randomized, placebo-controlled trial (ASSERT). Arthritis Rheum 2005:52:582-91.

10. van der Heijde D, Han C, DeVlam K, Burmester G, van den Bosch F, Williamson P, et al. Infliximab improves productivity and reduces workday loss in patients with ankylosing spondylitis: results from a randomized, placebo-controlled trial. Arthritis Rheum 2006;55:569-74.

11. Baraliakos $\mathbf{X}$, Brandt J, Listing J, Haibel H, Sorensen $H$, Rudwaleit M, et al. Outcome of patients with active ankylosing spondylitis after two years of therapy with etanercept: clinical and magnetic resonance imaging data. Arthritis Rheum 2005;53:856-63.

12. Davis JC Jr, van der Heijde DM, Braun J, Dougados M, Cush J, Clegg D, et al. Sustained durability and tolerability of etanercept in ankylosing spondylitis for 96 weeks. Ann Rheum Dis 2005; 64:1557-62.

13. Braun J, Baraliakos X, Brandt J, Listing J, Zink A, Alten R, et al. Persistent clinical response to the anti-TNF-alpha antibody infliximab in patients with ankylosing spondylitis over 3 years. Rheumatology (Oxford) 2005:44:670-6. 
14. Braun J, Brandt J, Listing J, Zink A, Alten R, Burmester G, et al. Two year maintenance of efficacy and safety of infliximab in the treatment of ankylosing spondylitis. Ann Rheum Dis 2005;64:229-34.

15. Baraliakos X, Listing J, Rudwaleit M, Brandt J, Alten R, Burmester G, et al. Safety and efficacy of readministration of infliximab after long-term continuous therapy and withdrawal in patients with ankylosing spondylitis. J Rheumatol 2007;34:510-15

16. van der Heijde D, Kivitz A, Schiff MH, Sieper J, Dijkmans BA, Braun J, et al. Efficacy and safety of adalimumab in patients with ankylosing spondylitis: results of a multicenter, randomized, double-blind, placebo-controlled trial. Arthritis Rheum 2006;54:2136-46.

17. Davis JC Jr, Revicki D, van der Heijde DM, Rentz AM, Wong RL, Kupper H, et al. Health-related quality of life outcomes in patients with active ankylosing spondylitis treated with adalimumab: results from a randomized controlled study. Arthritis Rheum 2007; 57:1050-7.

18. Revicki DA, Luo MP, Wordsworth P, Wong RL, Chen N, Davis JC Jr; for the ATLAS Study Group. Adalimumab reduces pain, fatigue, and stiffness in patients with ankylosing spondylitis: results from the Adalimumab Trial Evaluating Long-term Safety and Efficacy for Ankylosing Spondylitis (ATLAS). J Rheumatol 2008;35:1346-53.

19. van der Linden S, Valkenburg HA, Cats A. Evaluation of diagnostic criteria for ankylosing spondylitis. A proposal for modification of the New York criteria. Arthritis Rheum 1984;27:361-8.

20. Anderson JJ, Baron G, van der Heijde D, Felson DT, Dougados M. Ankylosing spondylitis assessment group preliminary definition of short-term improvement in ankylosing spondylitis. Arthritis Rheum 2001;44:1876-86.

21. van der Heijde D, Dougados M, Davis J, Weisman MH, Maksymowych W, Braun J, et al. ASsessment in Ankylosing Spondylitis International Working Group/Spondylitis Association of America recommendations for conducting clinical trials in ankylosing spondylitis. Arthritis Rheum 2005;52:386-94.

22. Jenkinson TR, Mallorie PA, Whitelock HC, Kennedy LG, Garrett SL, Calin A. Defining spinal mobility in ankylosing spondylitis (AS). The Bath AS Metrology Index. J Rheumatol 1994;21:1694-8.

23. Calin A, Garrett S, Whitelock H, Kennedy LG, O'Hea J, Mallorie P, et al. A new approach to defining functional ability in ankylosing spondylitis: the development of the Bath Ankylosing Spondylitis Functional Index. J Rheumatol 1994;21:2281-5.

24. Garrett S, Jenkinson T, Kennedy LG, Whitelock H, Gaisford P, Calin A. A new approach to defining disease status in ankylosing spondylitis: the Bath Ankylosing Spondylitis Disease Activity Index. J Rheumatol 1994;21:2286-91.
25. Heuft-Dorenbosch L, Spoorenberg A, van Tubergen A, Landewe R, van der Tempe $\mathrm{H}$, Mielants $\mathrm{H}$, et al. Assessment of enthesitis in ankylosing spondylitis. Ann Rheum Dis 2003;62:127-32.

26. Doward LC, Spoorenberg A, Cook SA, Whalley D, Helliwell PS, Kay LJ, et al. Development of the ASOLL: a quality of life instrument specific to ankylosing spondylitis. Ann Rheum Dis 2003;62:20-6.

27. McHorney CA, Ware JE Jr, Raczek AE. The MOS 36-Item Short-Form Health Survey (SF-36): II Psychometric and clinical tests of validity in measuring physical and mental health constructs. Med Care 1993;31:247-63.

28. Braun J, Brandt J, Listing J, Zink A, Alten R, Burmester G, et al. Long-term efficacy and safety of infliximab in the treatment of ankylosing spondylitis: an open, observational, extension study of a three-month, randomized, placebo-controlled trial. Arthritis Rheum 2003;48:2224-33.

29. Schiff MH, Burmester GR, Kent JD, Pangan AL, Kupper H, Fitzpatrick SB, et al Safety analyses of adalimumab (HUMIRA) in global clinical trials and US postmarketing surveillance of patients with rheumatoid arthritis. Ann Rheum Dis 2006;65:889-94.

30. Furst DE, Schiff MH, Fleischmann RM, Strand V, Birbara CA, Compagnone D, et al. Adalimumab, a fully human anti tumor necrosis factor-alpha monoclonal antibody, and concomitant standard antirheumatic therapy for the treatment of rheumatoid arthritis: results of STAR (Safety Trial of Adalimumab in Rheumatoid Arthritis). J Rheumatol 2003;30:2563-71.

31. Weinblatt ME, Keystone EC, Furst DE, Moreland LW, Weisman MH, Birbara CA, et al. Adalimumab, a fully human anti-tumor necrosis factor alpha monoclonal antibody, for the treatment of rheumatoid arthritis in patients taking concomitant methotrexate: the ARMADA trial. Arthritis Rheum 2003:48:35-45.

32. Keystone EC, Kavanaugh AF, Sharp JT, Tannenbaum H, Hua Y, Teoh LS, et al. Radiographic, clinical, and functional outcomes of treatment with adalimumab (a human anti-tumor necrosis factor monoclonal antibody) in patients with active rheumatoid arthritis receiving concomitant methotrexate therapy: a randomized, placebo-controlled, 52-week trial. Arthritis Rheum 2004;50:1400-11.

33. van de Putte LB, Atkins C, Malaise M, Sany J, Russell AS, van Riel PL, et al. Efficacy and safety of adalimumab as monotherapy in patients with rheumatoid arthritis for whom previous disease modifying antirheumatic drug treatment has failed. Ann Rheum Dis 2004;63:508-16.

34. Mease PJ, Gladman DD, Ritchlin CT, Ruderman EM, Steinfeld SD, Choy EH, et al. Adalimumab for the treatment of patients with moderately to severely active psoriatic arthritis: results of a double-blind, randomized, placebo-controlled trial. Arthritis Rheum 2005;52:3279-89.

\section{Keep up to date: sign up for our alerting services}

Find out automatically when an article is published on a specific topic or by a particular author. We can also alert you when an article is cited or if an eLetter or correction is published. You can also choose to be alerted when a new issue is published online [and when we post articles Online First]. Check out the New Content Alerts and Citation tracker from the Online tools section on the home page. 